\title{
Los Sainetes de Sor Juana Inés de la Cruz
}

\section{Sainete de Palacio}

Gor Juana gusta de interpretar, de hurgar más allá de lo real y $\omega$ concreto, con las metáforas. Su cuadro interpretativo de la vida en la corte pudo hacerse de diversa manera. Pudo partir de la impresión y sus sentimientos concomitantes. Pudo dar asi un cuadro claro, envuelto en una nebulosa en que aparecerían veladas formas y colorido. No así en Sor Juana. La neblina poética de su sainete tenía que ser rota por figuras que se destacan clara y diáfanamente, sin ser revestidas de color; es más: sin tener meollo humano.

Son figuras que aparecen en sucesión meditada, para volver a hundirse, dando un espectáculo para el cual la palabra espectáculo resulta contradictoria, pues es más bien un círculo de pensamientos, hechos humanidad teórica.

Olvidó el recuerdo de esta corte, que en ella tenía que despertar crítica acerba, no admiración; olvidó los recuerdos muy frescos y cercanos e hizo que dominara la razón, línea directriz de su calidad poética.

Al llegar a este punto de coordinación lógica, conceptual, ¿ahondó en cada razonamiento, para extraer aún más realidad, más causa del efecto observado? No hizo tal cosa. Le bastó organizar y ver la belleza de tal orden, orden barroco por supuesto, lleno de recovécos y retruécanos que dan al carácter estático de los conceptos puros, movilidad aparente, pero adicional, superpuesta.

En este hecho vemos, pues, la primera reminiscencia de su vida urbana, porque "en sus sainetes pone de relieve su condición 
burlesca sobre los hechos idiomáticos que la rodean; por concreto el ofensor, fué abstracta la defensa y general el ataque". 1

Hubo un fuerte contraste entre los primeros años de su vida de joven, en el campo, y su,vida de mujer, sedienta de cultura y saber. El contraste no pudo ser mayor. $Y$ el choque entre la vida intelectual, teórica e ideal de los libros y el contraste de las intrigas, falsedades y demás vicios cortesanos, crea un nuevo contraste que en un espíritu vivaz, como el de Sor Juana, tenía que producir complejidades intelectuales $y$ sentimentales dentro de su personalidad en formación. No hay que olvidar que vivió en la corte,-en una época en que el carácter es susceptible de toda clase de cambios: los cambios $\mathrm{y}$ las inquietudes de la adolescencia. Su posición destacada, șu personalidad, capaz de despertar envidias en cualquier medio y más en un medio como el cortesano, complicó más aún ese aspecto.

Las reacciones son imprescindibles. Son también necesarias, pero en un ambiente de tal diplomacia, cortesía y falsedad, no era posible expresar los pensamientos. Así deducimos que cuanto más fuertes eran éstos, más recónditos tenían que estar, más tenía que ocultarlos aquella cuyo corazón gritaba contra semejante sociedad. Claro está que al llegar a presentar el núcleo de lo inicuo, tenía que estar más alejado de la realidad y a ello se debe en parte que Sor Juana haya hecho esta abstracción tan artificiosa.

"El español de la época quiso no la realidad del ideal, sino el ideal de la realidad." 2 (Y Sor Juana participaba de esta cualidad, dado el nexo que va de ella hacia el gongorismo.)

Esto, porque la realidad nisma no interesa y no debe interesar al espíritu barroco. $Y$ esta forma convenia más que ninguna para que Sor Juana expresara su inconformidad, que era una inconformidad en el espacio y en el tiempo.

Veamos qué fué lo que quiso expresar.

Divide los entes metafísicos en dos grupos, con una figura intermedia. Hay dos entes humanos, los que, aun yendo encubiertos en palacio, no han podido ocultar su calidad de ser sentimientos verdaderos. Son el Amor y la Esperanza.

Los otros dos entes, son figuras que ya pertenecen a la sociedad refinada y llena de retorcimientos y lo demuestran a las claras en la forma de su diálogo. Son la Fineza y el Obsequio, figuras muy. de palacio. 
La figura central o intermedia es neutral y no se inclina mucho hacia uno u otro lado: es el Respeto, cualidad que en si dirige todo el pequeño sainete, dedicado a la virreina doña María Luisa Gonzaga.

El primer grupo demuestra la condición de sentimientos tan humanos como el Amor y la Esperanza, cuando entran en la corte. El segundo grupo expresa cómo estos entes se valen de su condición; para merecer algo tan poco apetecible y tan de la corte, como el desprecio; regalo que sólo en la corte llega a valer algo, que por lo tanto sólo reviste, una existencia artificial.

Queda el Respeto, con su condición especial de personaje orgulloso que se siente muy en su lugar dondequiera que sea y desde luego, también en la corte, sin que esto evite el ser rechazado por el Alcalde, muy categóricamente. Es significativo que el Alcalde reparta algo que sólo alcanza aquel que no lo merece.

El Amor, tímido pretendiente, sólo se atreve a entrar cubierto, pues como tal no debería estar en la corte y si allí está, es tan sólo como amor artificial, de galanteo, parecido a aquel amor de trovadores cortesanos; pues su calidad humana, verdadera, tuvo que dejarla afuera, ya que el amor no es merecedor, siquiera, del desprecio, en este mundo cruel y falso. Contiene toda la amargura del ser que ve mal pagados los sentimientos verdaderos, ya en él mismo, ya por observación en los demás.

Entra el personaje antitético, el Obsequio, el cual no pretende ocultarse, pues se siente en suelo propio. Con un juego de palabras muy fino se le rechaza.

El Respeto, con la cónsciencia de ser el personaje de más prestigio, entra airoso; pero lo rechazan, ya que su misma índole le veda el derecho de pedir:

La Fineza pretende también, como el Obsequio y la Cortesía, con mucha seguridad; pero se descubre, por su mismo carácter de. Fineza, la paradoja que reside en que el fino no pretende, así como tampoco el cortés ni el obsequioso.

El caso de la Fineza es aún más grave, pues como tal, ni siquiera debería decir que lo es. Esto seguramente preocupaba a un espíritu libre y orgulloso como el de Sor Juana, que se sentía muy en su derecho de mostrar quién era y que con su enérgico temperamento, llegó hasta contestar con dureza a una superiora, al ver que ella no estaba en lo justo. 
La figura que más insinúa el carácter humano - por lo tanto, plebeya- es la Esperanza: esta pobre Esperanza, que no deberia pisar el suelo de la corte y que, al entrar, se disfraza como desconfianza, ya que la desconfianza es cualidad del "discreto". Ella, humilde y con lógica al mismo tiempo, hace la deducción de que es merecedora del desprecio aquel que en la corte se atreve a tener esperanza.

Pero con esto pierde: el desprecio significa un valor dentro de palacio, y no podrá ganar un premio una indiscreta, como la Esperanza misma, con acre sinceridad afirma, que es, en palacio.

Todo el juego se resume en la frase fina, irónica, de "que no merece el premio quien lo pretende". ${ }^{4} \mathrm{El}$ Amor es regalo; el .Obsequio queda premiado, con tal que se le tolere; el Respeto no puede pedir, pues constantemente esta en deuda; la Fineza, como tal, no puede ver como merecimiento ni lo menos merecible; la Esperanza, en sí, ni siquiera merece estar en aquel lugar. Y concluye el Alcalde:

\footnotetext{
Pues sepan que en Palacio, los que 10 asisten, aun los mismos desprecios son imposibles.
}

\section{Sainete segundo}

El segundo sainete es algo completamente distinto en su exterior; pero, en realidad, es sólo una variante del primero.

Si aquél hablaba del desprecio de las damas, éste habla del desprecio del público, que silba la obra misma que están comentando algunos personajes populares, de los cuales Arias dice, muy con el espiritu del murmurador, que el veneno que lleva en el pecho maná agradablemente y lo desahoga al salir.

Empieza una burla acerba, en la que se critica la obra comenzando por el hecho que se haya exhibido obra tan mala, sólo por ser nueva. Afirma que era más presentable la Celestina, desde el momento en que venía de España. Parece encajar aquí el antiguo resentimiento y complejo del criollo, del cual no se pudo salvar Sor Juana, como lo afirma Ermilo Abreu Gómez. Resalta su burla, al hablar del ceceo de uno de los personajes, Muñiz, quien dice que no sabe pronunciar la "S". 
El autor, Acebedo, pide a los silbadores cordel para ahorcarse y le dan soga; seguirá hablando un trecho más. Estos juegos de palabras, tan característicos de. Sor Juana, son igualmente difíciles de interpretar con toda su trascendencia. Baste, pues, con lo visible, pues tan pronto es juego intelectual y gracejo, como es deseo de expresar algo más recóndito.

Los dos sainetes están impregnados, saturados, de la fina y dinámica personalidad de Sor Juana, que al ocultar su crítica, dice aún más que si la expresara.

ILSE HECKEL, Universidad de México.

\section{B I B L I O G R A F I A}

1. Abreu Gómez, Ermiro. "Sor Juana Inés de la Cruz." Clásicos, Romónticos, Modernos. Ediciones Botas. México, 1934.

2. Arreu Gómez, Ermilo. Prólogo a Sor Inana Inés de la Cruz. Poesias. Clásicos de México, Ediciones Botas, 1940.

3. Jiménez Rueda, Julio. Prólogo a Sor Juana Inés de la Cruz. Los empeños de una casa.

Ediciones de la Universidad Nacional Autónoma. México, 1940.

4. Jrménez Rueda; Julro. Cap. vi. Historia de la Literatura Mexicana. Ediciones Botas. México, 1942.

6. Monterde, Francisco. Nota preliminar y Notas Sor Juana Inés de la Cruz. Sainetes.

El Hijo Pródigo Vol. xi. Núm. 35. Febrero de 1946.

6. Monterde, Francisco. Nota preliminar y Notas. Sor Juana Inés de la Cruz. Sainetes. Editora Intercontinental. México, 1945.

7. CRUz, Sor JuANa INÉS DE LA. Sainetes. Editora Intercontinental. México, 1945.

8. CRUz, Sor Junana INÉs de la. Los empeños de una casa. Ediciones de la Universidad Nacional Autónoma. México, 1940.

9. Molins, Antonio Eufías de. Biografía. Notas Bibliográficas y juicios críticos de escritores españoles y americanos. Poesias escogidas de Sor Juana Inés de la Cruz. Casa Editorial Araluce. Barcelona. $2^{\mathrm{a}}$ ed. (sin fecha). 


\section{NOTA S}

1 Abreu Gómez. Prólogo a Sor Juana Inés de la Cruz. Idem., pág. 89.

2 Abreu Gómez. Idem., pág. 63.

3 Sor Juana Inés de la Cruz. Sainetes. Idem., pág. 16.

4 Sor Juana Inés de la Cruz. Irem., pág. 18. 